\title{
Triazine-cored polymeric vectors for antisense oligonucleotide delivery in vitro and in vivo
}

\author{
Mingxing Wang ${ }^{*}$, Bo Wu, Jason D. Tucker, Sapana N. Shah, Peijuan Lu and Qilong Lu
}

\begin{abstract}
Background: The polymer-based drug/gene delivery is promising for the treatment of inherent or acquire disease, because of the polymer's structural flexibility, larger capacity for therapeutic agent, low host immunogenicity and less cost. Antisense therapy is an approach to fighting genetic disorders or infections using antisense oligonucleotides (AOs). Unfortunately, the naked AOs showed low therapeutic efficacy in vivo and in clinical trial due to their poor cellular uptake and fast clearance in bloodstream. In this study, a series of triazine-cored amphiphilic polymers (TAPs) were investigated for their potential to enhance delivery of AOs, 2'-O-methyl phosphorothioate RNA (2'-OMePS) and phosphorodiamidate morpholino oligomer (PMO) both in vitro and in vivo.

Results: TAPs significantly enhanced AO-induced exon-skipping in a GFP reporter-based myoblast and myotube culture system, and observed cytotoxicity of the TAPs were lower than Endoporter, Lipofectamine-2000 or PEI 25K. Application of optimized formulations of TAPs with AO targeted to dystrophin exon 23 demonstrated a significant increase in exon-skipping efficiency in dystrophic $\mathrm{mdx}$ mice. The best ones for PMO and 2'-OMePS delivery have reached to 11-, 15-fold compared with the $\mathrm{AO}$ only in $m d x$ mice, respectively.
\end{abstract}

Conclusion: The study of triazine-cored amphiphilic polymers for $\mathrm{AO}$ delivery in vitro and in $m d x$ mice indicated that the carrier's performances are related to the molecular size, compositions and hydrophilic-lipophilic balance (HLB) of the polymers, as well as the AO's structure. Improved exon-skipping efficiency of AOs observed in vitro and in $m d x$ mice accompanied with low cytotoxicity demonstrated TAP polymers are potentials as safe and effective delivery carrier for gene/drug delivery.

Keywords: Triazine, Amphiphilic cationic polymers, Antisense delivery, Exon-skipping, Muscular dystrophy

\section{Introduction}

Antisense therapy is an approach to fighting genetic disorders or infections using short DNA-like molecules called antisense oligonucleotides (AOs). Duchenne muscular dystrophy (DMD) is an X-linked, lethal neuromuscular disorder caused by mutations in the dystrophin gene affecting 1 in approximately 5000 males at birth [1]. It is the most common childhood form of muscular

${ }^{*}$ Correspondence: mingxing.wang@atriumhealth.org McColl-Lockwood Laboratory for Muscular Dystrophy Research, Carolinas Medical Center, 1000 Blythe Blvd., Charlotte, NC 28231, USA dystrophy (MD) and around $50 \%$ of all MD cases, and the patients usually die in their late 20s [2, 3]. Fundamental treatments of DMD requires either correction or replacement of the mutated gene to restore function. In recent years, $\mathrm{AO}$-mediated exon-skipping has been a promising therapy for treating DMD by facilitating "Skipping" of specific dystrophin gene exon(s), thus to correct specific genetic mutations and restore production of dystrophin protein [4-13]. Among the several AO macromolecules, 2' $O$-methyl-phosphorothioate RNA (2'$\mathrm{OMePS}$ ) and phosphorodiamidate morpholino oligomers (PMO) have been deeply studied in clinical trials. The 
$2^{\prime}$-OMePS is resistant to nuclease degradation and relatively stable in biological systems compared with natural DNA and RNA, but the presence of negatively charged phosphate groups may restrict their overall uptake [14, 15], additionally the toxicity has limited its ceiling dose for clinic. Meanwhile, PMO, is a neutral molecule under physiological condition, having the deoxyribose rings replaced with morpholino linked through phosphorodiamidate intersubunits, exhibiting excellent stability and lower toxicity compared with other counterparts $[16,17]$. However, the relatively charge-neutral nature of PMOs associated with poor cellular uptake and fast clearance in bloodstream has been identified as a major obstacle to delivery efficacy. These impediments together suggest that an imperative challenge in $\mathrm{AO}$ exon-skipping is to improve delivery performance with minimizing toxicity $[5,18,19]$.

To improve delivery efficiency, chemically modification has been studied, such as: (1) Arginine-rich cell penetrating peptides or octaguanidine dendrimer have been conjugated into PMO, and substantial improvement in delivery has been reported in $m d x$ mice, leading to near normal levels of dystrophin expression in bodywide muscles [4, 9-11]. (2) Peptide modified 2'-OMePS improved uptake in skeletal and cardiac muscle [20]. However, the densely packed positive charges are associated with higher toxicity, making further clinical application difficulty [11]. Furthermore, the complicated synthesis and purification in covalent modification make it more expensive, and potential peptide-related immune responses could prevent repeated administration.

The polymer-based drug/gene delivery is promising for the treatment of inherent or acquire disease, because of the polymer's structural flexibility, larger capacity for therapeutic agent, low host immunogenicity and less cost than viral one [21-24]. Amphiphilic polymers developed for gene delivery by our group and others have demonstrated enhanced gene transfection in skeletal muscles [25-35]. Recently, a set of triazine-cored amphiphilic polymers (TAPs) constructed from Jeffamine $M$ series and low molecular weight polyethyleneimine (LPEI) were prepared by combinatorial chemistry and characterized for pDNA delivery in vitro and in vivo [34], which can condense DNA efficiently with nanosized particles below $200 \mathrm{~nm}$ at the weight ratio 5 of polymer/pDNA, being stable in the presence of serum. The introduction of amphiphilic Jeffamine led to a significant increase in the cellular uptake of complexes with higher transfection efficiency in $\mathrm{CHO}, \mathrm{C} 2 \mathrm{C} 12$, and HSkMC cell lines, but without toxicity increasing against parent LPEI. The best polymer-formulated pDNA delivery produced transgene expression efficiency 6-, 29-fold of PEI 25k-mediated in vitro and in $m d x$ mice, respectively.
Motived by the promising performances of TAPs for pDNA delivery, we investigated them for AO delivery in vitro and in dystrophic $m d x$ mice in this study. The results demonstrated that TAPs obviously improved AOinduced exon-skipping efficiency compared with Lipofectamine-2000 (LF-2k) or Endoporter (a commercially available reagent for PMO delivery) in vitro, and significantly enhanced dystrophin expression with the AO targeting the mutated mouse dystrophin exon 23 achieved also when administered in $m d x$ mice. Higher efficiency and less toxicity indicated the potential of the TAP polymers as AO delivery vector for the treatment of DMD or other genetic diseases.

\section{Materials and methods \\ Materials}

Dulbecco's modified Eagle's medium (DMEM), penicillin-streptomycin, fetal bovine serum (FBS), L-glutamine and HEPES [4-(2-hydroxyethyl)-1-piperazineethanesulfonic acid] buffer solution (1 M) were purchased from Thermo Fisher Scientific (Waltham, MA, USA). 3-(4,5-Dimethylthiazol-2-yl)-5-(3carboxymethoxyphenyl)-2-(4-sulfophenyl)-2 $\mathrm{H}$-tetrazolium (MTS) was bought from BioVision Inc. (Milpitas, CA, USA). Phosphorodiamidate morpholino oligomer PMOE50 (5'-GGGATCCAGTATACTTACAGGCTC C-3') targeting human dystrophin gene exon 50, PMOE23 (5'-GGCCAAACCTCGGCTTACCTGAAAT-3') targeting mouse dystrophin gene exon 23 and Endo-porter were purchased from Gene Tools (Philomath, OR, USA). An arbitrary single-stranded 20-mer deoxyoligonucleotide with the sequence 5'-GGCCAAACCTCGGCTTAC CT-3' (phosphodiester), for the physicochemical study of polymer-oligonucleotide polyplex. AOs modified by 2'-O-methylation and phosphorthioation 2'-OMePSE50 (5'-GGGAUCCAGUAUACUUACAGGCUCC-3') targeting human dystrophin gene exon 50, 2'-OMePSE23 (5'GGCCAAACCUCGGCUUACCU- $3^{\prime}$ ) targeting mouse dystrophin gene exon 23 used for delivery in vitro and in vivo were purchased from GenScript (Piscataway, NJ, USA). Other chemicals were obtained from SigmaAldrich Co. (St Louis, MO, USA) unless otherwise stated. The TAPs were prepared previously by us [34].

\section{Cell viability assay}

Cytotoxicity was evaluated in C2C12E50 cell line using the MTS assay [30-35]. The relative cell viability was calculated by: $\left(A_{\text {treated }}-A_{\text {background }}\right) \times 100 /\left(A_{\text {control }}-A_{\text {background }}\right)$, the absorbance $(\boldsymbol{A})$ was measured at $570 \mathrm{~nm}$ using a Tecan 500 Plate reader (Tecan US, Inc, Morrisville, NC, USA) to obtain the metabolic activity of the cell. Untreated cells were taken as controls with $100 \%$ viability and wells without cells as blanks, and all viability assay was carried out in triplicate. 


\section{In vitro transfection}

The C2C12E50 myoblast and C2C12E23 differentiated cells lines expressing the reporter GFP was used in this study. The expression of GFP was controlled by the effective skipping of the inserted human dystrophin exon 50 sequence (hDysE50), mouse dystrophin exon 23 sequence (mDysE23), respectively [27].

\section{C2C12E50}

The $\mathrm{C} 2 \mathrm{C} 12 \mathrm{E} 50$ cell line was maintained in $10 \% \mathrm{FBS}$ DMEM in a humidified $10 \% \mathrm{CO}_{2}$ incubator at $37{ }^{\circ} \mathrm{C}$. About $5 \times 10^{4} \mathrm{C} 2 \mathrm{C} 12 \mathrm{E} 50$ cells per well in $500 \mu \mathrm{L}$ medium was seeded and allowed to grow until a confluence of $70 \%$. Cell culture medium was replaced before addition of polymer/AO formulation with varying ratios. PEI 25K, LF-2k and Endoporter used as comparisons. Transfection efficiencies indicated by GFP production were recorded after 4-day incubation with the Olympus IX71 fluorescent microscope and digital images taken with the DP Controller and DP Manager software (Olympus America Inc., Centre Valley, PA, USA). Transfection efficiency was also examined quantitatively using fluorescence-activated cell sorting (FACS) Calibur flow cytometer (BD, Franklin Lakes, NJ, USA).

\section{C2C12E23}

The cell culture and delivery protocol are the same as in C2C12E50, the images were taken, and cell collected after 6-day treatment.

\section{In vivo delivery}

This study was carried out in strict accordance with the National Institutes of Health Guide for the Care and Use of Laboratory Animals. The protocols were approved by the Institutional Animal Care and Use Committee (IACUC), Carolinas Medical Center (Breeding protocol 10-13-07A; Experimental protocol 10-13-08A). The Mice were free of standard pathogens. All injections were performed under isoflurane anesthesia, and all efforts were made to minimize suffering $[10,11,27]$.

\section{Animals and injections}

Dystrophic $m d x$ mice (C57BL/10 as genetic background) aged $4-5$ weeks were used for in vivo testing $[5$ mice per group, mixed male/female (m/f), $3 \mathrm{~m}+2 \mathrm{f}$ or $2 \mathrm{~m}+3 \mathrm{f}$ in the test and control groups] unless otherwise stated. Mice were killed by $\mathrm{CO}_{2}$ inhalation at desired time points, and muscles and other tissues were snap-frozen in liquid nitrogen cooled isopentane and stored at $-80{ }^{\circ} \mathrm{C}$. The $2^{\prime}$-OMePSE23 (5'-GGCCAAACCUCGGCUUAC CU-3') and PMOE23 (5'-GGCCAAACCTCGGCTTAC CTGAAAT-3') targeting the boundary sequences of exon and intron 23 of the mouse dystrophin gene were used.
For intramuscular (i.m.) injections, $5 \mu \mathrm{g}$ 2'-OMePSE23 or $2 \mu \mathrm{g}$ PMOE23 with or without polymer was used in $40 \mu \mathrm{L}$ saline for each tibialis anterior (TA) muscle. For intravenous (i.v.) injection, $1 \mathrm{mg}$ PMOE23 with or without polymer used in $100 \mu \mathrm{L}$ saline. The muscles were examined 2 weeks later and all of tissues were processed with the operator blinded to the treatment groups.

\section{Immunohistochemistry and histology}

Serial sections of $6 \mu \mathrm{m}$ were cut from the treated mice muscles. The sections were stained with a rabbit polyclonal antibody P7 for the detection of dystrophin protein as reported previously [17, 20, 36-38]. Polyclonal antibodies were detected by goat anti-rabbit IgG Alexa 594 (Invitrogen, Carlsbad, CA, USA). The counting number of dystrophin-positive fibers in a single cross-section was addressed using the Olympus BX51 fluorescent microscope (Olympus America Inc., Centre Valley, PA, USA). Section were also stained with hematoxylin and eosin (H\&E) for histological assessment.

\section{RT-PCR for in vivo samples}

Total RNA was extracted from the muscle after dissection, and $100 \mathrm{ng}$ of RNA template was used for a $50 \mu \mathrm{L}$ RT-PCR with the Stratascript One-Tube RT-PCR System (Stratagene, Santa Clara, CA). Ex20Fo 5'-CAGAATTCT GCCAATTGCTGAG-3' and Ex26Ro 5'-TTCTTCAGC TTGTGTCATCC-3' for amplification of mRNA from exons 20 to 26 . The intensity of the bands obtained from the treated $m d x$ mice muscles was measured and compared with that from normal muscles of C57BL/6 mice by Image J software version 1.42 (National Institutes of Health, Bethesda, MD, USA), and percentage of exon skipping was calculated with the intensity of the two bands representing both exon 23 unskipped and skipped as $100 \%$. Unskipped band included exon 23 is $1093 \mathrm{bp}$, skipped band without exon 23 is $880 \mathrm{bp}$.

\section{Transmission electron microscopy}

The polymer/AO polyplex solution containing $1 \mu \mathrm{g}$ of $\mathrm{AO}$ was prepared at a designated weight ratio in $100 \mu \mathrm{L} 0.9 \%$ saline and analyzed using transmission electron microscopy (TEM; JEM-1400Plus TEM by JEOL USA, Inc.) with AMT-XR80S-B wide angle side Mount 8MPixel, CCD Camera. The samples were prepared using negative staining with $1 \%$ phosphotungstic acid [30-35]. 


\section{Statistical analysis}

All the data was expressed as mean $\pm S D$, and the data were analyzed using Two-tailed $t$-test with a value of $p \leq 0.05$ being considered statistically significant.

\section{Results and discussion}

\section{Synthesis and characterization of triazine-cored}

\section{amphiphilic polymers (TAPs)}

The synthesis and characterization of TAPs have been reported in our previous study [34]. The structure and code of Jeffamine $M$ series, LPEI, and corresponding structures of the TAPs are presented as supplementary in Additional file 1: Figure S1 and Table S1, respectively.

\section{Cytotoxicity}

The cytotoxicity of TAPs in C2C12E50 cells was evaluated by MTS assay (Fig. 1). PEI cytotoxicity was molecular size-dependent with higher Mw PEI exhibiting higher toxicity. The PEI 25k showed high cytotoxicity with cell viability around 20\%; while LPEI $2 \mathrm{k}$ gave much lower toxicity with over $60 \%$ cell alive at the dose of $25 \mu \mathrm{g} / \mathrm{mL}$, which indicated that LPEI $(0.8 \mathrm{k}, 1.2 \mathrm{k}$ and $2.0 \mathrm{k})$ is much lower toxicity than the high Mw PEI 25k [30-35]. Cell viability with all of the TAPs at the dose of $25 \mu \mathrm{g} / \mathrm{mL}$ was similar to or a little higher than that of their parental LPEIs, and all showed lower toxicity than PEI $25 \mathrm{k}$ at the lowest dose of $5 \mu \mathrm{g} / \mathrm{mL}$. The cytotoxicity under high dose of $25 \mu \mathrm{g} / \mathrm{mL}$ was in the order from higher to lower: $A_{3}>A_{4} ; 1 A_{1} 1 B_{3}>1 A_{1} 1 B_{2}>1 A_{1} 1 B_{1}$; $1 \mathrm{~A}_{3} 1 \mathrm{~B}_{3} \geq 1 \mathrm{~A}_{1} 1 \mathrm{~B}_{3}>1 \mathrm{~A}_{4} 1 \mathrm{~B}_{3} \geq 1 \mathrm{~A}_{2} 1 \mathrm{~B}_{3}$; $2 \mathrm{~A}_{3} 1 \mathrm{~B}_{3} \geq 1 \mathrm{~A}_{3} 2 \mathrm{~B}_{3}>1 \mathrm{~A}_{3} 1 \mathrm{~B}_{3}$. The level of toxicity was associated with PEI content and HLB of the TAPs. The lower HLB the molecule has, the more hydrophobic it is. The HLB of the A series is in the order $\mathrm{A} 2>\mathrm{A} 4>\mathrm{A} 3>\mathrm{A} 1$. The PEI size is in the order: B3 (PEI $2 \mathrm{k})>\mathrm{B} 2 \quad(\mathrm{PEI} 1.2 \mathrm{k})>\mathrm{B} 1 \quad$ (PEI 0.8k). TAPs with more and/or bigger size PEI and more hydrophobic showed

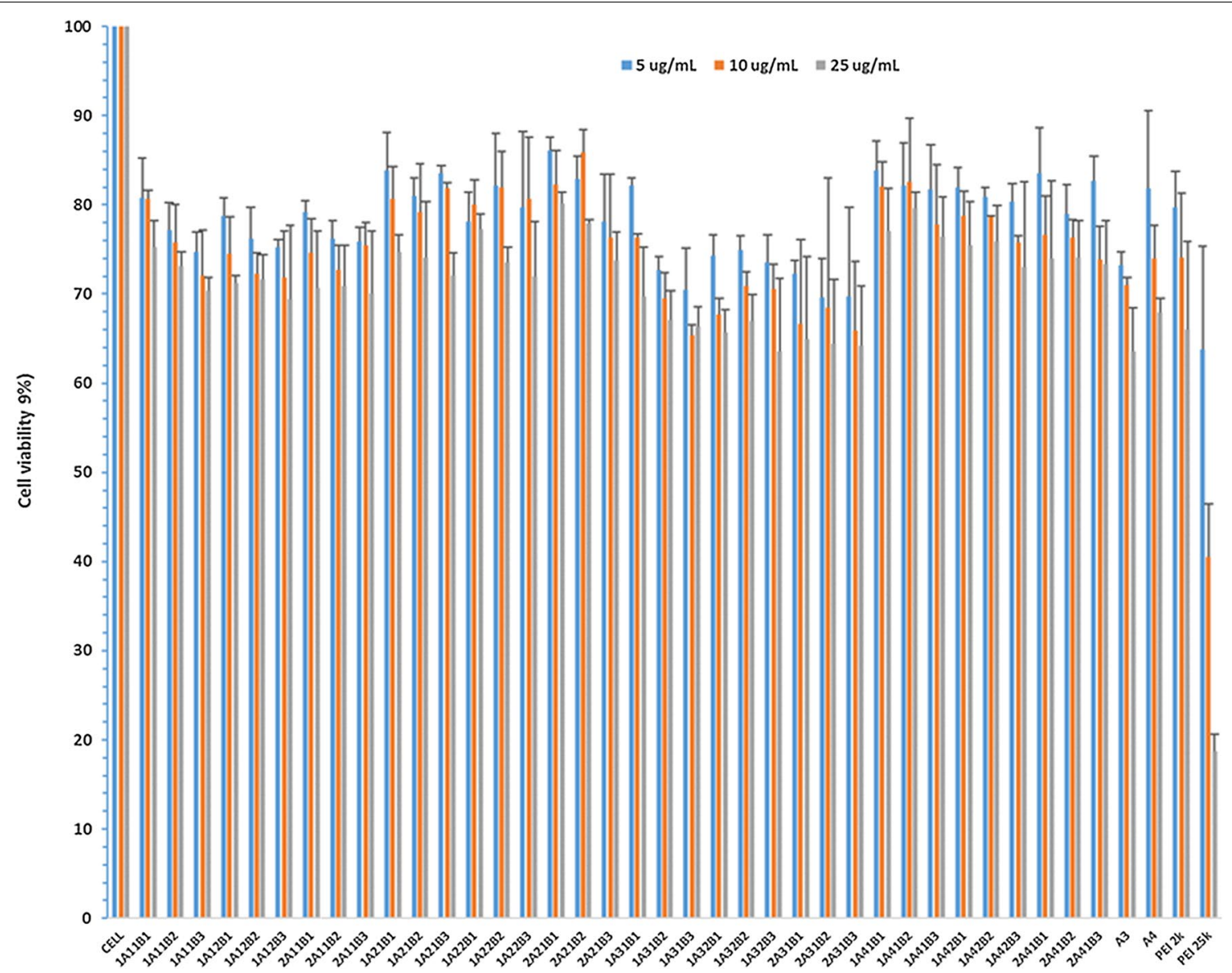

Fig. 1 Cell viability of C2C12E50 myoblasts after treatment with TAPs at 3 doses (5, 10,25 $\mu \mathrm{g} / \mathrm{mL}$; PEl 25k as control) determined by MTS assay. Cells were seeded in 96-well plate at an initial density of $1 \times 10^{4}$ cells/well in $0.2 \mathrm{~mL}$ growth media. The results are presented as the mean \pm SD in triplicate 
relatively elevated toxicity. Toxicity of all polymers was dose-dependent, but the levels of toxicity with TAPs were consistently much lower when compared with PEI 25k at the same dose. This improved cyto-compatibility is probably attributed to the low-toxicity of the building blocks, and the possible steric hindrance of Jeffamines reducing positive charge density of PEI, thereby leading to a decrease of the average protonation constant of the polymers [39].

\section{Evaluation of 2'-OMePS and PMO delivery in vitro}

In this study, the C2C12E50 myoblast and C2C12E23 differentiated cells expressing the reporter GFP upon differentiation were used for in vitro study. The expression of GFP in the cells were interrupted by the insertion of the human dystrophin exon 50 (hDyse50), or mouse dystrophin exon 23 (mDysE23) within the GFP coding sequence. Restoration of GFP expression relied on the targeted removal of exon(s) through exon-skipping by AOs [40, 41].

\section{Negatively charged 2'-OMePS delivery in C2C12E50 myoblast cell}

We first examined the effect of TAPs on exon-skipping of $2^{\prime}$-OMePS in the C2C12E50 cell line. The AO sequence (5'-GGGAUCCAGUAUACUUACAGGCUCC-3') targeting the inserted human dystrophin exon 50 within the GFP coding region was used. The cells were treated with the $2^{\prime}$-OMePSE50 at a fixed amount $(4 \mu \mathrm{g} / \mathrm{mL})$ formulated with each TAP at different dosage. Transfection efficiency (TE) of formulated 2'-OMePSE50 was visualized under fluorescence microscopy analysis after 4-day delivery. The delivery efficiency of TAPs (at the dose of 10 to $20 \mu \mathrm{g} / \mathrm{mL}$ ) formulated 2'-OMePS were measured quantitatively by flow cytometry (Fig. 2). Delivery efficiency was observed over $50 \%$ with $1 \mathrm{~A}_{1} 1 \mathrm{~B}_{3}, 1 \mathrm{~A}_{1} 2 \mathrm{~B}_{3}, 2 \mathrm{~A}_{1} 1 \mathrm{~B}_{3}$, $2 \mathrm{~A}_{3} 1 \mathrm{~B}_{2}, 1 \mathrm{~A}_{3} 2 \mathrm{~B}_{3}$ and $2 \mathrm{~A}_{3} 1 \mathrm{~B}_{3}$ and over $65 \%$ with $2 \mathrm{~A}_{1} 1 \mathrm{~B}_{3}$, $1 A_{3} 2 B_{3}$ and $2 A_{3} 1 B_{3}$. In contrast, $2^{\prime}-O M e P S$ alone, and 2'-OMePS formulated with PEI 25k or LF-2k exhibited around $1.5 \%, 12.6 \%$ and $35.2 \%$ GFP positive cells, respectively, at the optimal concentrations. The $2^{\prime}$-OMePS with the best TAP formulation achieved the highest efficiency with over 44-fold of that achieved with 2'-OMePS alone.

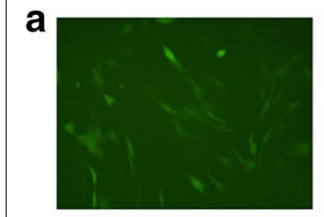

$1 A_{s} 2 B_{s}(5 \mu g)$

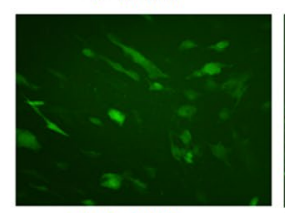

$1 A_{1} 2 B_{2}(5 \mu g)$

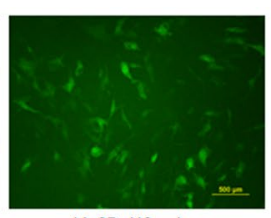

$1 A_{3} 2 B_{3}(10 \mu g)$

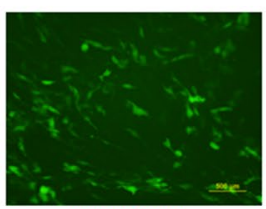

$1 A_{1} 2 B_{2}(10 \mu g)$

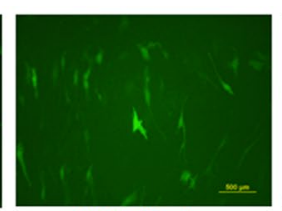

$1 A_{s} 1 B_{s}(10 \mu g)$

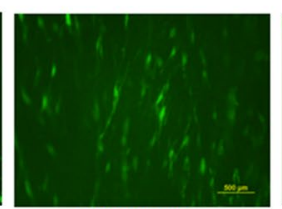

$1 A_{1} 2 B_{3}(5 \mu g)$

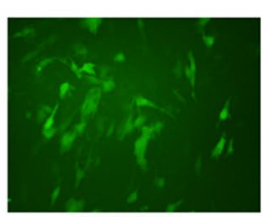

$2 A_{s} 1 B_{s}(5 \mu g)$

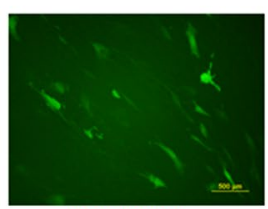

$1 A_{1} 2 B_{3}(10 \mu g)$

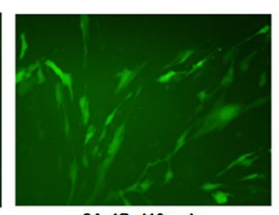

$2 A_{s} 1 B_{s}(10 \mu g)$

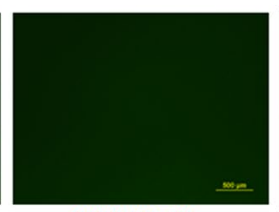

2'-OMePS only

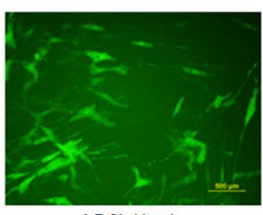

$\mathrm{LF}-2 \mathrm{k}(4 \mu \mathrm{g})$

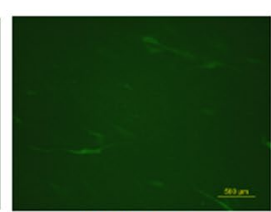

PEI 25k (5 $\mu \mathrm{g})$
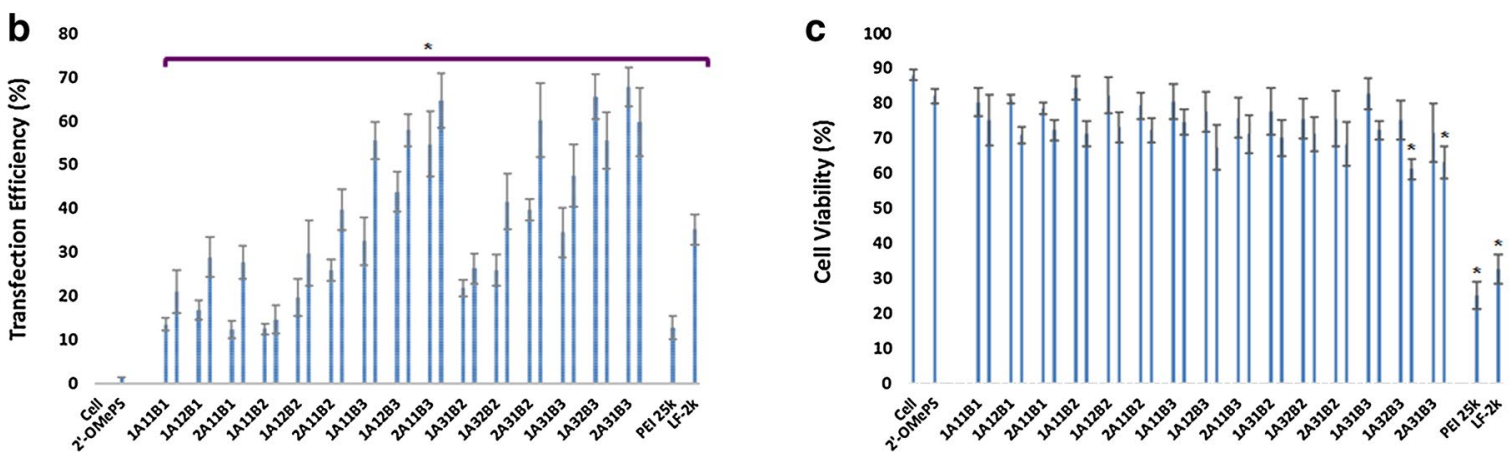

Fig. 2 Delivery efficiency and toxicity of TAP/2'-OMePS E50 complexes in a C2C12E50 cell line determined by fluorescence microscopy and fluorescence-activated cell sorting (FACS) analysis. a Representative fluorescence images of 2'-OMePS E50-induced exon-skipping in C2C12E50 cell line. (The images were taken 4-day after treatment. Original magnification $\times 200$; scale bar $500 \mu \mathrm{m}$ ). b Statistical date of TE of $2^{\prime}$-OMePS E50 formulated with TAP (Student's $t$-test, ${ }^{*} p \leq 0.05$ compared with $2^{\prime}$-OMePS E50 only). c Cell viability (Student's t-test, ${ }^{*} p \leq 0.05$ compared with untreated cell as control). In this test, $2 \mu \mathrm{g} 2^{\prime}$-OMePS E50 was formulated with TAPs (5 and $\left.10 \mu \mathrm{g}\right)$, and PEI 25 (5 $\left.\mu \mathrm{g}\right), \mathrm{LF}-2 \mathrm{k}(4 \mu \mathrm{g})$ formulated as comparison in $0.5 \mathrm{~mL}$ 10\% FBS-DMEM medium, respectively. The results are presented as the mean \pm SD in triplicate 
Clearly, the results suggest that a combination of amphiphilic part and cationic ingredients together are preferred as carrier to enhance delivery efficiency of $2^{\prime}$-OMePS. In agreement with the viability results from polymer alone, cytotoxicity of the TAP/2'-OMePS complexes was dramatically lower than that of PEI 25k or LF-2k formulated 2'-OMePS complexes. These results are in line with that for pDNA delivery [34]: the more hydrophobic $A_{1} /$ $A_{3}$-based (lower HLB) ones showed more effective than the more hydrophilic $\mathrm{A}_{2} / \mathrm{A}_{4}$-based TAPs (higher HLB, all were below $10 \%$, data not given here), and more positive ones (2B composed TAPs; $\mathrm{B} 3$ composed $>\mathrm{B} 2$ composed $>$ B1 composed TAPs, correspondingly) demonstrated more effective also, further demonstrated the complicate interactions between TAP and 2'-OMePS including charge and hydrophobic interaction.

The transduction and cytotoxicity were further exemplified by staining with Propidium iodide (PI) and Hoechst 33342 after 6-day transfection (Additional file 1: Figure S2). The delivery efficiency of $2 \mathrm{~A}_{3} 1 \mathrm{~B}_{3}$ formulated $2^{\prime}$-OMePS was much higher than LF-2k mediated one at the optimum condition based on our early study $[32,34$, 35 ], while the toxicity was much lower than LF-2k, even $2 \mathrm{~A}_{3} 1 \mathrm{~B}_{3}$ 's dose was 2.5 times of LF- $2 \mathrm{k}$. This further indicates the advantage of TAPs as carrier of oligonucleotide delivery against LF-2k, which is probably due to TAP's amphiphilicity and moderate positive charges.

\section{Uncharged PMO delivery in C2C12E50 myoblast cell}

C2C12E50 cells were treated with $10 \mu \mathrm{g} / \mathrm{mL}$ PMOE50 (5'-AACTTCCTCTTTAACAGAAAAGCATAC-3') formulated with each polymer at two doses $(10,20 \mu \mathrm{g} / \mathrm{mL})$ in $0.5 \mathrm{~mL} 10 \% \mathrm{FBS}-\mathrm{DMEM}$, and the TE was determined by fluorescence microscopy and FACS after 4-day treatment as for 2'-OMePS E50 (Fig. 3). PMOE50 formulated with polymer $1 \mathrm{~A}_{1} 1 \mathrm{~B}_{1}, 1 \mathrm{~A}_{1} 2 \mathrm{~B}_{1}, 2 \mathrm{~A}_{1} 1 \mathrm{~B}_{2}, 1 \mathrm{~A}_{1} 1 \mathrm{~B}_{3}, 1 \mathrm{~A}_{1} 2 \mathrm{~B}_{3}$, $2 \mathrm{~A}_{1} 1 \mathrm{~B}_{3}$, and $1 \mathrm{~A}_{3} 2 \mathrm{~B}_{3}$ reached TE over $60 \%$, and the better ones were hit by $1 \mathrm{~A}_{1} 2 \mathrm{~B}_{3}$ and $2 \mathrm{~A}_{1} 1 \mathrm{~B}_{3}$ close to or over $80 \%$, comparing with Endoporter-mediated reaching $70 \%$ and PMO alone with around 4\%. These levels of GFP expression of best TAP-mediated PMO were approximately 20 -fold greater than that achieved by PMO alone. Cytotoxicity of the amphiphilic TAPs formulated PMO at this dose remained low, with more than $70 \%$ of cell surviving rate for all TAPs. In contrast, PEI 25K or Endoporter kept around $30 \%$ and $65 \%$ cell alive at a dose of $10 \mu \mathrm{g} / \mathrm{mL}$, respectively. On the other hand, the more hydrophilic $\mathrm{A}_{2} /$ $\mathrm{A}_{4}$-based TAPs gave much better efficacy for PMO delivery compared with that for $2^{\prime}-\mathrm{OMePS}$ or pDNA [30-35], although a little lower than the more hydrophobic $A_{1} /$ $\mathrm{A}_{3}$-based TAPs. The overall performances both in efficiency and cytotoxicity are related to the size and HLB of the TAPs. This is directed by much higher exon-skipping efficiency obtained with $1 \mathrm{~A}_{1} 1 \mathrm{~B}_{1}, 1 \mathrm{~A}_{1} 2 \mathrm{~B}_{1}, 2 \mathrm{~A}_{1} 1 \mathrm{~B}_{2}, 1 \mathrm{~A}_{1} 1 \mathrm{~B}_{3}$, $1 \mathrm{~A}_{1} 2 \mathrm{~B}_{3}, 2 \mathrm{~A}_{1} 1 \mathrm{~B}_{3}$, and $1 \mathrm{~A}_{3} 2 \mathrm{~B}_{3}$, which indicated the complicated relationship between the polymer composition and delivery activity to delivery cargos: (1) The amphiphilic nature of TAPs are important to complex with delivery cargos to form stable and effective particles; (2) The TAPs with moderate size and bigger or more PEI content are preferred as negatively charged pDNA or 2'-OMePS delivery carrier; (3) The positive charge of polymers for delivering uncharged PMO is not so imperative as delivering negatively charged pDNA or oligonucleotides, but moderate charged amphiphilic TAPs improved the sizematched PMO delivery efficiency probably through TAP/ PMO complex particles formed by hydrophobic-hydrophobic interaction and additional hydrogen-bond with dispersed positive surface, leading to TAP/PMO complex more flexible and more preferable to improve cellular uptake.

\section{PMO delivery in C2C12E23 differentiated cell}

To evaluate the delivery potential of the TAPs for PMO exon-skipping in muscle fibers, the TAPs were further tested in the mouse dystrophin exon 23 reporter $\mathrm{C} 2 \mathrm{C} 12$ cell (C2C12E23). The C2C12E23 reporter construct uses a muscle creatine kinase (MCK) promoter to drive the GFP expression, thus allowing us to evaluate more cell-type exon-skipping of AOs in differentiating or differentiated myotubes [41]. Cells reaching around $70 \%$ confluence were incubated in 10\% FBS media for 2 days and then treated with TAPs formulated PMOE23. The PMOE23 (5'-GGCCAAACCTCGGCT TACCTGAAAT- $3^{\prime}$ ) targeting the boundary sequences of exon and intron 23 of mouse dystrophin gene was used here. We exemplified the $1 \mathrm{~A}_{4} 1 \mathrm{~B}_{2}$ with more hydrophilic nature and better performance in $\mathrm{C} 2 \mathrm{C} 12 \mathrm{E} 50$ cell line as model at three doses $(10,20$ and $40 \mu \mathrm{g} / \mathrm{mL})$ formulated PMOE23 $(10 \mu \mathrm{g} / \mathrm{mL})$ per our previous study, and the TE

\footnotetext{
(See figure on next page.)

Fig. 3 Delivery efficiency and toxicity of TAP/PMOE50 complexes in a C2C12E50 cell line determined by fluorescence microscopy and flow cytometry. a Representative fluorescence images of PMOE50-induced exon-skipping in C2C12E50 cell line. (The images were taken 4-day after treatment. Original magnification $\times 200$; scale bar $200 \mu \mathrm{m}$ ). $\mathbf{b}$ Statistical date of TE of PMOE50 formulated with TAP (Student's $t$-test, ${ }^{*} p \leq 0.05$ compared with PMO only). c Cell viability (Student's $t$-test, ${ }^{*} p \leq 0.05$ compared with untreated cell as control). In this test, $5 \mu \mathrm{g}$ PMOE50 was formulated with TAPs $(10 \mu \mathrm{g})$, and PEI $25(5 \mu \mathrm{g})$, Endoporter $(5 \mu \mathrm{g})$ formulated as comparison in $0.5 \mathrm{~mL}$ 10\% FBS-DMEM medium, respectively. The results are presented as the mean \pm SD in triplicate
} 


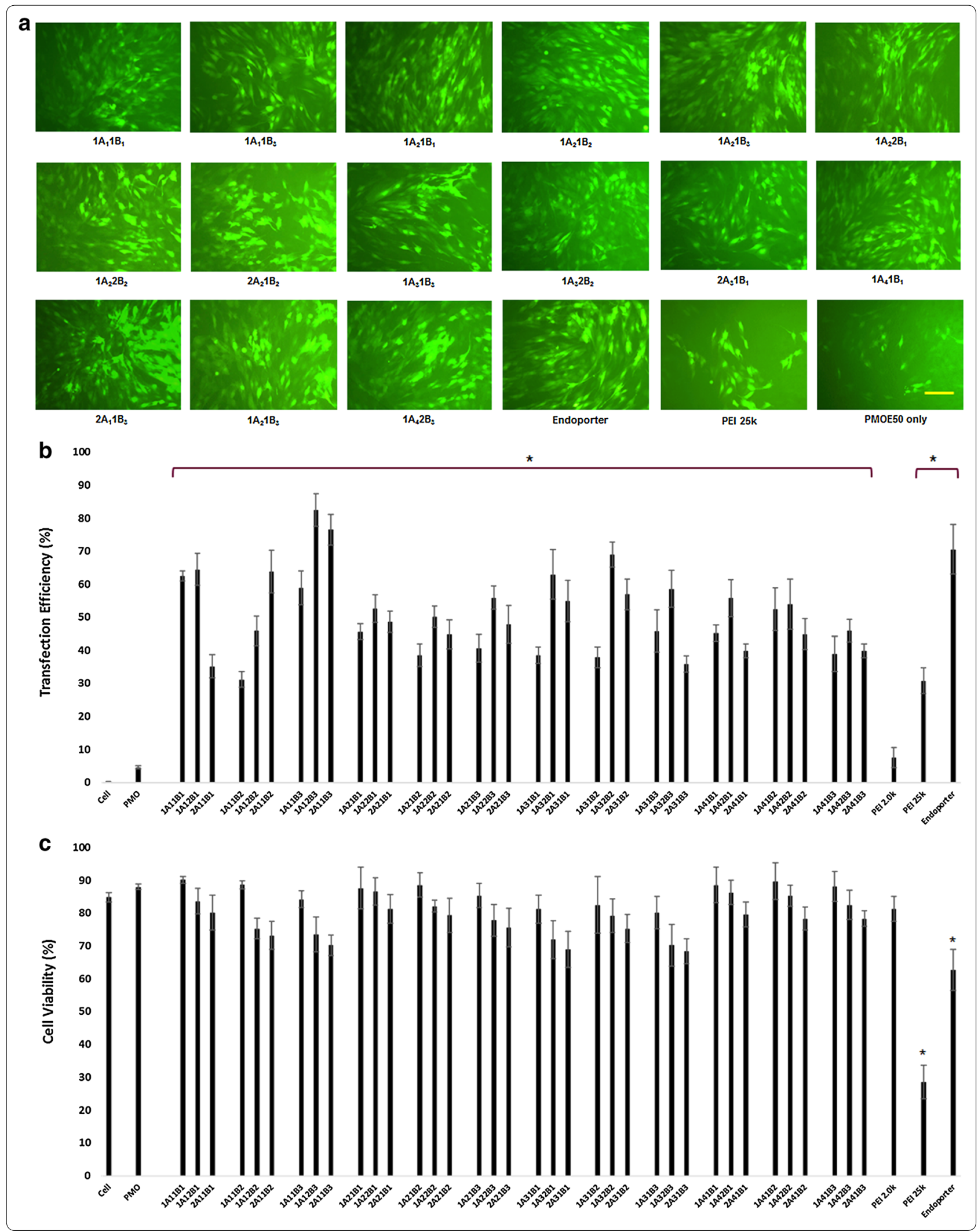


was visualized by fluorescence microscopy after 6-day treatment. The results demonstrated that the $1 \mathrm{~A}_{4} 1 \mathrm{~B}_{2}$ enhanced exon-skipping of PMO as compared to PMO alone, the dose-dependent efficacy to differentiated cells was observed, and no toxicity detected under the tested dosage as illustrated images in Fig. 4. The delivery efficiency at the dosage of 20 or $40 \mu \mathrm{g} / \mathrm{mL}$ is comparable or higher than Endoporter achieved.

Our study showed A2/A4-based TAPs with lower efficiency for pDNA and 2'-OMePS delivery in cell culture and in vivo delivery [30-35]. However, the same TAPs were highly effective for PMO delivery with enhanced exon-skipping. The reason for such an apparent difference in TAP-mediated delivery for pDNA, $2^{\prime}$-OMePS and PMO are unclear, but the differences in chemical nature, molecular size and delivery mechanism existing among these three therapeutic cargos are mostly responsible. The negatively charged pDNA or 2'-OMePS requires more positively charged polymeric vector to condense a complex stable for effective delivery, leading to the polymer/cargo polyplex's particle size and surface charge under same weight ratio is completely different. Instead, TAPs and uncharged PMO may form complex through primarily hydrophobic interactions, and may assemble high order superstructure. This has been demonstrated in our early study that the lipophilic interaction between amphiphilic polymer and uncharged PMO might therefore be one of the critical factors to enhance PMO delivery $[30,31,33,35]$. In addition, positively charged groups within the TAPs might not only play a key role for the interaction with PMO through hydrogen-bonds, but it could afford the polyplex particles in a physiological environment a longer circulation half-life also than PMO alone. This may well lead to a higher serum tolerance and improvement in the uptake of PMO through the vasculature and cell membrane, therefore more effective delivery of PMO into muscles.

\section{Transmission electron microscopy (TEM)}

To better understanding the delivery action of polymer-mediated AOs, we exemplified the TAP polymers: $1 \mathrm{~A}_{3} 1 \mathrm{~B}_{2}, 1 \mathrm{~A}_{3} 2 \mathrm{~B}_{2}, 2 \mathrm{~A}_{3} 1 \mathrm{~B}_{2}$ and $1 \mathrm{~A}_{4} 1 \mathrm{~B}_{2}$, and corresponding
TAP/AO polyplexes $\quad\left(\mathrm{TAP} / \mathrm{PMO}=10 / 5 ; \quad \mathrm{TAP} / 2^{\prime}-\right.$ $\mathrm{OMePS}=10 / 2$ based on the in vitro results) examined intuitively under transmission electron microscopy (TEM). The followings are illustrated in Fig. 5: (1) The polymer TAPs alone formed smaller particles via selfassembly with different size either more hydrophobic $\left(2 \mathrm{~A}_{3} 1 \mathrm{~B}_{2}\right)$ or more hydrophilic $\left(1 \mathrm{~A}_{4} 1 \mathrm{~B}_{2}\right)$ likely due to its amphiphile composition. (2) The PMO oligonucleotides alone formed particles with the size below $50 \mathrm{~nm}$, that is most likely a result of hydrophobic interactions among PMO molecules; while the 2'-OMePS only formed different size particles due to the aggregation. (3) The polyplex of TAP/PMO at weight ratio of $10 / 5$ formed spherical particles larger than the corresponding TAP alone with an average diameter around $40-70 \mathrm{~nm}$, that is mainly due to the hydrophobic interaction and hydrogen-bonds between the PMO and polymer. (4) The TAP/2'-OMePS at weight ratio of $10 / 2$ polyplex gave slightly smaller particles compared with TAP/PMO probably due to the additional charge-charge interaction. (5) The more hydrophobic $1 \mathrm{~A}_{3} 1 \mathrm{~B}_{2} / \mathrm{AO}$ complex showed smaller particle size than the more hydrophilic $1 \mathrm{~A}_{4} 1 \mathrm{~B}_{2} / \mathrm{AO}$ complex one. (6) The more positive $1 \mathrm{~A}_{3} 2 \mathrm{~B}_{2} / \mathrm{AO}$ complex gave smaller or condensed particle compared with the less positive $1 \mathrm{~A}_{3} 1 \mathrm{~B}_{2} / \mathrm{AO}$ complex. These results coincident with our previous reported that the more hydrophobic and more cationic polymers achieved more condensed nanoparticles with oligonucleotides [30-35]. The interaction between polymer and oligonucleotides is important to affect their delivery performances into cells or tissues, the nanosized polyplex particles should help to overcome biological barriers, increase cellular uptake, and enhance escape from membrane compartments [36-38].

\section{Delivery of AOs with TAPs in vivo Local delivery}

In view of the above results that all TAPs showed improved delivery performance for AO exon-skipping, accompanied by much lower cytotoxicity compared with PEIs in vitro, we firstly evaluated them in vivo via intramuscular (i.m.) injection of AOE23 formulated with TAP

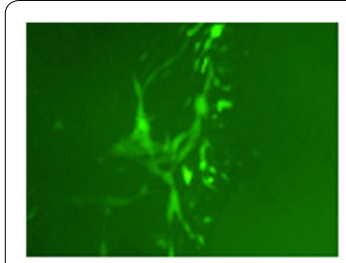

$1 A_{1} 1 B_{2}(5 \mu g)+P M O$

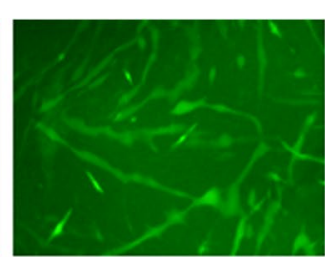

$1 \mathrm{~A}_{4} 1 \mathrm{~B}_{2}(10 \mu \mathrm{g})+\mathrm{PMO}$

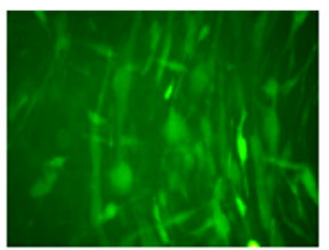

$1 \mathrm{~A}_{8} 1 \mathrm{~B}_{2}(20 \mu \mathrm{g})+\mathrm{P} M O$

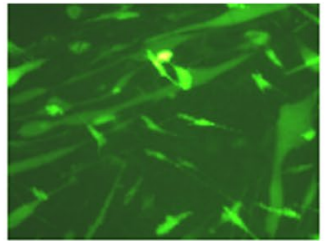

Endoporter $(5 \mu \mathrm{g})+\mathrm{P} M O$

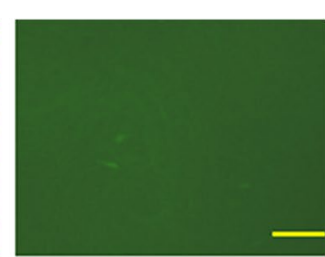

PMOE23 only

Fig. 4 Green fluorescent protein expression induced by PMOE23 $(5 \mu \mathrm{g})$ formulated with $1 \mathrm{~A}_{4} 1 \mathrm{~B}_{2}$ dose-dependent in $\mathrm{C} 2 \mathrm{C} 12 \mathrm{E} 23 \mathrm{Cells}$ in $0.5 \mathrm{~mL}$ of 10\% FBS-DMEM after 6-day treatment. Original magnification × 200; scale bar $200 \mu \mathrm{m}$ 


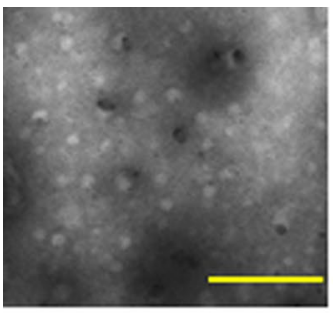

$2 \mathrm{~A}_{3} 1 \mathrm{~B}_{2}+2$ '-OMePS

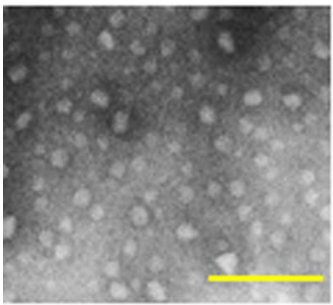

$2 \mathrm{~A}_{3} 1 \mathrm{~B}_{2}+\mathrm{PMO}$

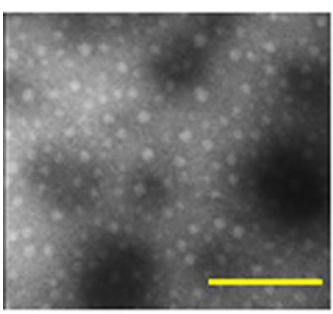

$2 \mathrm{~A}_{3} 1 \mathrm{~B}_{2}$

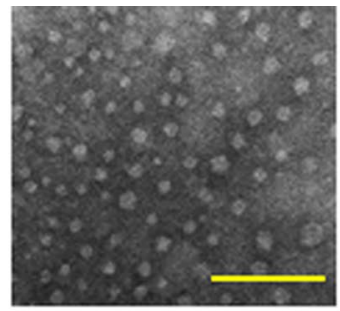

$1 \mathrm{~A}_{4} 1 \mathrm{~B}_{2}+2$ '-OMePS

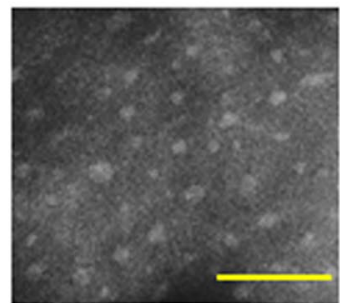

$1 A_{4} 1 B_{2}+P M O$

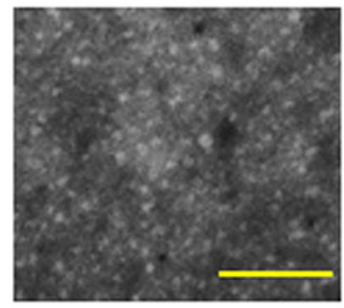

$1 A_{4} 1 B_{2}$

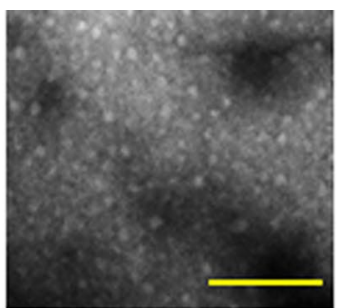

$1 \mathrm{~A}_{2} 1 \mathrm{~B}_{2}+2$ '-OMePS

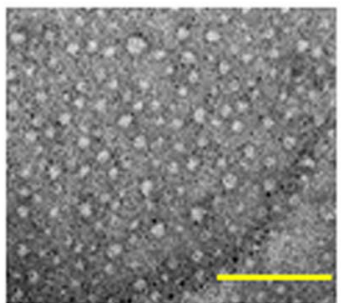

$1 \mathrm{~A}_{3} 1 \mathrm{~B}_{2}+\mathrm{PMO}$

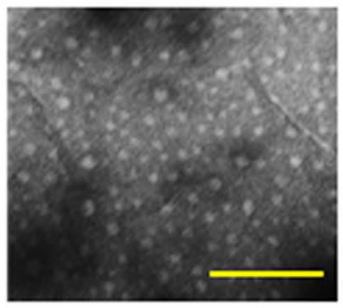

$1 \mathrm{~A}_{3} 1 \mathrm{~B}_{2}$

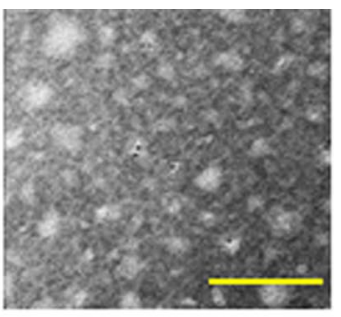

2'-OMePS only

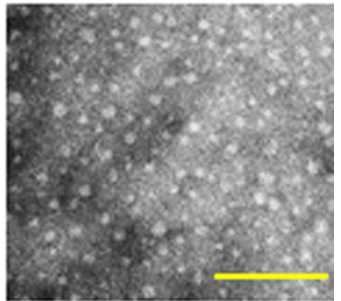

$1 \mathrm{~A}_{3} 2 \mathrm{~B}_{2}+\mathrm{PMO}$

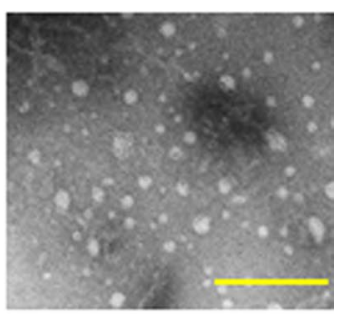

PMO only

Fig. 5 Negatively stained transmission electron micrographs of TAPs, PMO only, and TAPs (10 $\mu \mathrm{g})$ complexed with PMO $(5 \mu \mathrm{g})$ or $2^{\prime}-\mathrm{OMePS}(2 \mu \mathrm{g})$ (scale bar $100 \mathrm{~nm}$ )

polymers to tibialis anterior (TA) muscles of $m d x$ mice (aged 4-5 weeks). The $m d x$ mouse contains a nonsense mutation in exon 23 and prevents production of a functional dystrophin protein, whereas targeted removal of the mutated exon through exon-skipping, can restore the reading frame and expression of dystrophin protein.

\section{PMO Delivery}

Each TA muscle received $2 \mu \mathrm{g}$ PMOE23 formulated with $10 \mu \mathrm{g}$ TAP polymer in $40 \mu \mathrm{L}$ saline. The treated muscles were harvested 2 weeks after injection as our previous study [30-35]. Immunohistochemistry showed that PEI 2.0k, PEI 25k formulated PMO and PMO alone induced around $13 \%, 20 \%$, and $11 \%$ dystrophin positive fibers in one cross-section of the TA muscle, respectively. Dystrophin positive fibers increased dramatically in the muscles treated with TAP-formulated PMOE23. Such as, the dystrophin positive fibers being $41 \%, 35 \%, 54 \%$, $46 \%, 40 \%, 56 \%, 45 \%$ with the use of $2 \mathrm{~A}_{1} 1 \mathrm{~B}_{2}, 1 \mathrm{~A}_{3} 1 \mathrm{~B}_{2}$, $1 \mathrm{~A}_{3} 2 \mathrm{~B}_{2}, \quad 2 \mathrm{~A}_{3} 1 \mathrm{~B}_{1}, 1 \mathrm{~A}_{4} 1 \mathrm{~B}_{1}, \quad 1 \mathrm{~A}_{4} 1 \mathrm{~B}_{2}, \quad 1 \mathrm{~A}_{1} 1 \mathrm{~B}_{3}$ formulated $P M O$, respectively. Most significantly, the use of $1 \mathrm{~A}_{3} 2 \mathrm{~B}_{2}$,
$1 \mathrm{~A}_{4} 1 \mathrm{~B}_{2}$ formulated PMO reached up approximately fivefold of PMO alone (Fig. 6). The levels of exon-skipping confirmed with RT-PCR were $24.4 \%, 28.6 \%, 47.2 \%, 28.0 \%$, $34.1 \%, 35.0 \%, 55.7 \%, 38.2 \%$ and $13.8 \%$ for $2 \mathrm{~A}_{4} 1 \mathrm{~B}_{1}, 2 \mathrm{~A}_{1} 1 \mathrm{~B}_{2}$, $1 \mathrm{~A}_{4} 1 \mathrm{~B}_{2}, 1 \mathrm{~A}_{4} 1 \mathrm{~B}_{1}, 2 \mathrm{~A}_{3} 1 \mathrm{~B}_{1}, 1 \mathrm{~A}_{1} 1 \mathrm{~B}_{3}, 1 \mathrm{~A}_{3} 2 \mathrm{~B}_{2}, 2 \mathrm{~A}_{3} 1 \mathrm{~B}_{3}$ formulated PMO and PMO only, respectively. The exonskipped level is consistent with the visualized positive fibers, and further demonstrated that the amphiphilic nature (either more hydrophilic $\mathrm{A}_{2} / \mathrm{A}_{4}$-constructed TAPs or more lipophilic $A_{1} / A_{3}$-constructed TAPs) is crucial for the delivery of neutral-charged oligonucleotides PMO both in vitro and in vivo.

\section{2'-OMePS delivery}

Next, we evaluated the effects of the TAPs for negativecharged 2'-OMePSE23 delivery in vivo by i.m. injection. All TAPs were examined at the dose of $20 \mu \mathrm{g}$ mixed with $5 \mu \mathrm{g} 2^{\prime}$-OMePSE23 in $40 \mu \mathrm{L}$ saline, and the treated TA muscles were harvested 2 weeks after injection also. Immunohistochemistry showed that the numbers of dystrophin-positive fibers increased up to 3- to 15-folds 


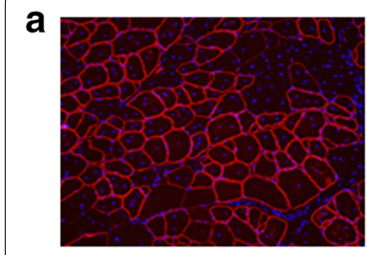

$1 \mathrm{~A}_{1} 1 \mathrm{~B}_{3}+\mathrm{PMO}$

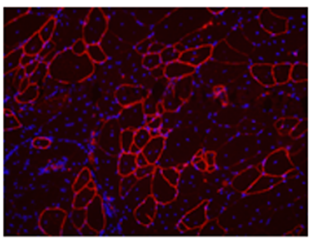

$1 \mathrm{~A}_{1} 2 \mathrm{~B}_{3}+\mathrm{PMO}$

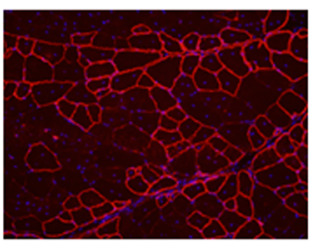

$2 \mathrm{~A}_{1} 1 \mathrm{~B}_{3}+\mathrm{PMO}$

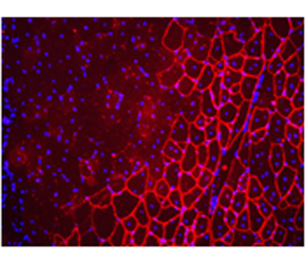

$1 A_{1} 1 B_{2}+P M O$

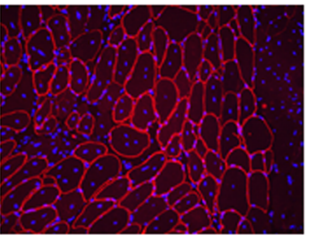

$1 \mathrm{~A}_{3} 2 \mathrm{~B}_{2}+\mathrm{PMO}$

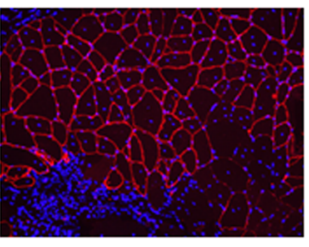

$2 \mathrm{~A}_{4} 1 \mathrm{~B}_{1}+\mathrm{PMO}$

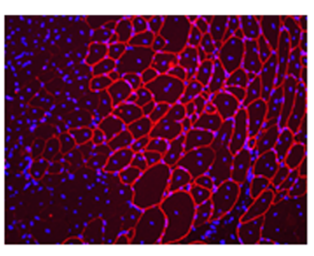

$1 \mathrm{~A}_{1} 2 \mathrm{~B}_{2}+\mathrm{PMO}$

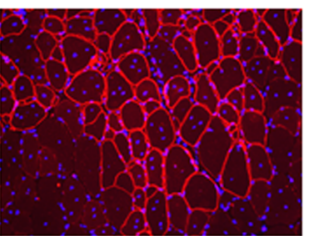

$2 \mathrm{~A}_{3} 1 \mathrm{~B}_{2}+\mathrm{PMO}$

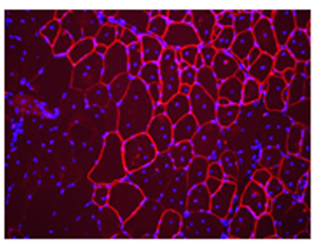

$1 \mathrm{~A}_{\imath} \mathrm{B}_{1}+\mathrm{PMO}$

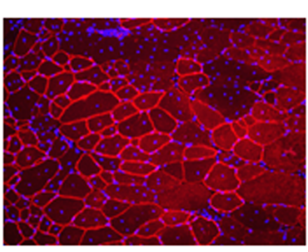

$1 \mathrm{~A}_{4} 1 \mathrm{~B}_{3}+\mathrm{PMO}$

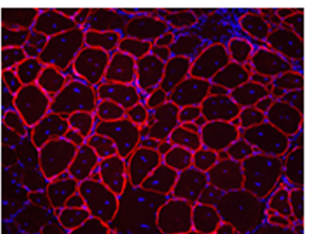

$1 \mathrm{~A}_{4} 1 \mathrm{~B}_{2}+\mathrm{PMO}$

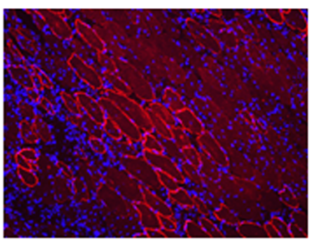

PEI 25k+PMO

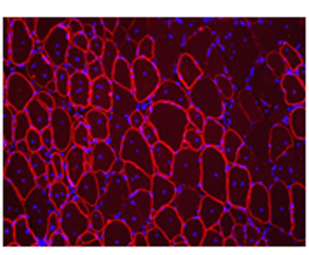

$1 \mathrm{~A}_{3} 1 \mathrm{~B}_{2}+\mathrm{PMO}$

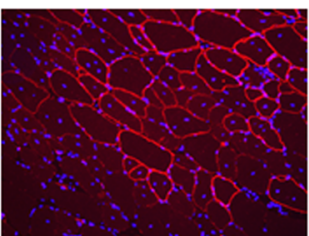

$1 \mathrm{~A}_{4} 2 \mathrm{~B}_{2}+\mathrm{PMO}$

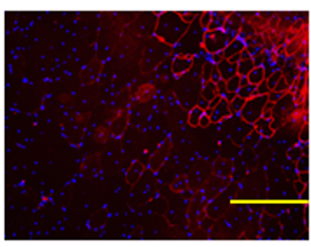

PMO

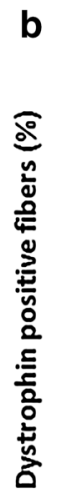

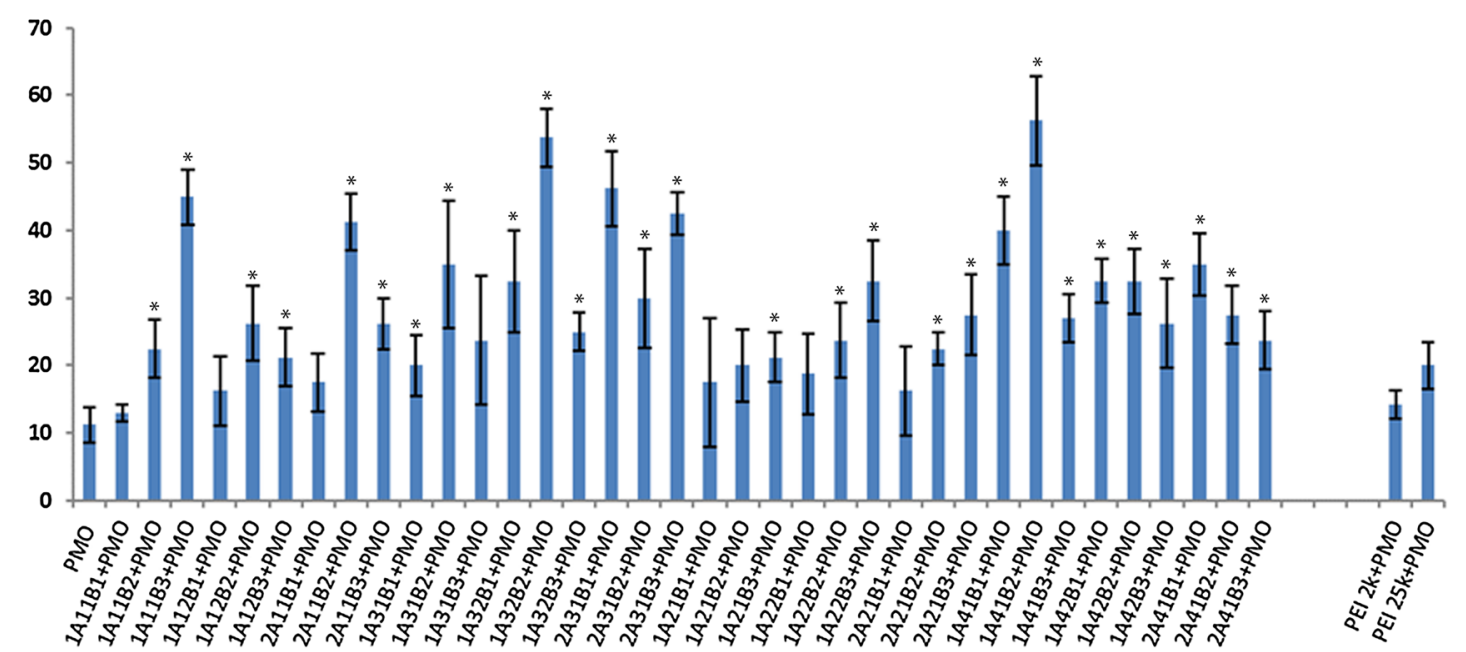

C

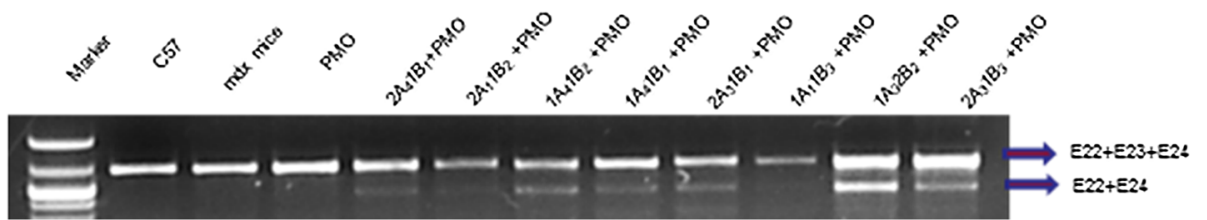

Fig. 6 Restoration of dystrophin in tibialis anterior muscles of $m d x$ mice (aged 4-5 weeks) 2 weeks after intramuscular injection with $10 \mu \mathrm{g}$ polymer formulated PMOE23 $(2 \mu \mathrm{g})$ in $40 \mu \mathrm{L}$ saline. Muscles treated with PMOE23 only was used as controls. a Dystrophin was detected by immunohistochemistry with rabbit polyclonal antibody P7 against dystrophin. Blue nuclear staining with 4,6-diamidino-2-phenylindole (original magnification $\times 200$; scale bar $200 \mu \mathrm{m}$ ). $\mathbf{b}$ The percentage of dystrophin-positive fibers (mean $\pm S D, n=5$, Two-tailed t-test, ${ }^{*} p \leq 0.05$ compared with PMO). c Detection of exon 23 skipping by RT-PCR. Total RNA of $100 \mathrm{ng}$ from each sample was used for amplification of dystrophin mRNA from exon 20 to exon 26. The upper bands (indicated by E22 + E23 + E24) correspond to the normal mRNA, and the lower bands (indicated by E22 + E24) correspond to the mRNA with exon E23 skipped 
in the muscles treated with same amount of $2^{\prime}$-OMePS formulated with TAP polymers. Particularly, dystrophinpositive fibers were induced to $30 \%, 44 \%, 35 \%, 40 \%$ and $32 \%$ with $1 \mathrm{~A}_{3} 2 \mathrm{~B}_{1}, 2 \mathrm{~A}_{3} 1 \mathrm{~B}_{1}, 2 \mathrm{~A}_{3} 1 \mathrm{~B}_{2}, 2 \mathrm{~A}_{3} 1 \mathrm{~B}_{3}, 1 \mathrm{~A}_{4} 1 \mathrm{~B}_{3}$ formulation, respectively. In contrast, PEI $25 \mathrm{k}$-mediated 2 -OMePS produced around $6 \%$ positive fibers (Fig. 7). On one hand, exceptionally, the $2 \mathrm{~A}_{3} 1 \mathrm{~B}$ series increased dystrophin induction more effectively for $2^{\prime}$-OMePSE23 delivery than other TAPs, probably due to its condensed particles and more favorable positive surface charge of TAP $/ 2$ '-OMePS polyplex, as demonstrated by TEM morphology. On the other hand, both more hydrophilic $\mathrm{A}_{2} /$ $\mathrm{A}_{4}$-constructed TAPs and more lipophilic $\mathrm{A}_{1} / \mathrm{A}_{3}$-constructed TAPs showed effective in vivo when compared with that only more hydrophilic $\mathrm{A}_{1} / \mathrm{A}_{3}$-constructed TAPs working in vitro. Furthermore, it indicates that there is gap in delivery performance between in vitro and in vivo. Overall, the delivery efficiency of $2^{\prime}$-OMePS is lower than a

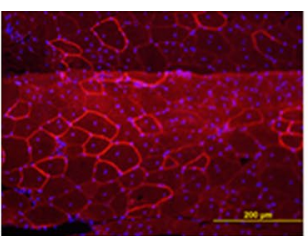

$1 \mathrm{~A}_{1} 1 \mathrm{~B}_{2}+2$ '-OMePS)

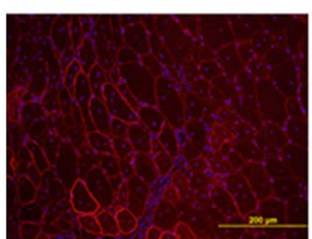

$2 \mathrm{~A}_{1} 1 \mathrm{~B}_{3}+2$ '-OMePS

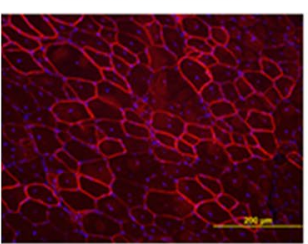

$2 \mathrm{~A}_{2} 1 \mathrm{~B}_{2}+2$ '-OMePS

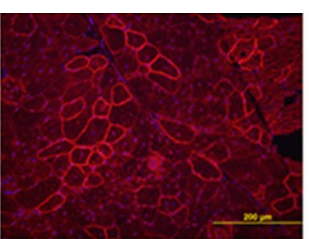

$1 \mathrm{~A}_{2} 1 \mathrm{~B}_{2}+$ 2'-OMePS $^{\prime}$

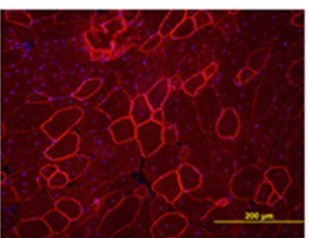

$1 \mathrm{~A}_{4} 1 \mathrm{~B}_{1}+2$ '-OMePS

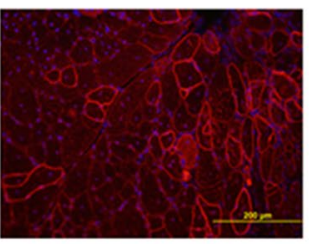

$1 \mathrm{~A}_{2} 2 \mathrm{~B}_{3}+2$ '-OMePS

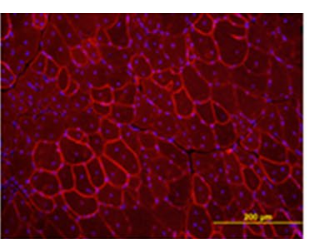

$1 \mathrm{~A}_{4} 1 \mathrm{~B}_{3}+$ 2'-OMePS $^{\prime}$

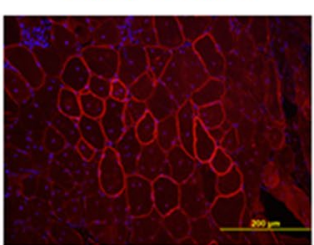

$1 \mathrm{~A}_{4} 2 \mathrm{~B}_{3}+2$ '-OMePS

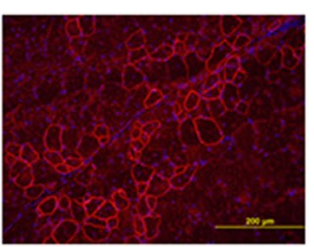

$1 \mathrm{~A}_{4} 2 \mathrm{~B}_{2}+2^{\prime}-\mathrm{OMePS}$

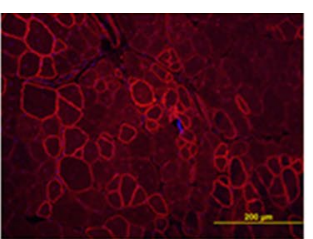

$1 \mathrm{~A}_{3} 2 \mathrm{~B}_{1}+2$ '-OMePS

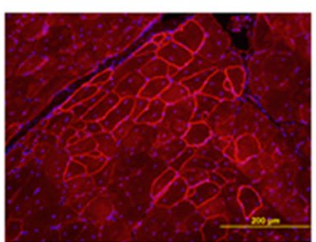

$1 \mathrm{~A}_{3} 2 \mathrm{~B}_{2}+2$ '-OMePS

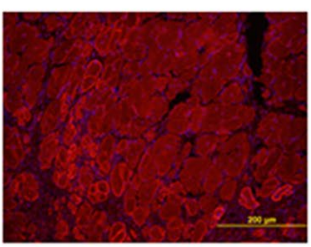

PEI 25k + 2'-OMePS

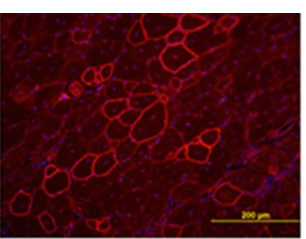

$2 \mathrm{~A}_{3} 1 \mathrm{~B}_{1}+2$ '-OMePS

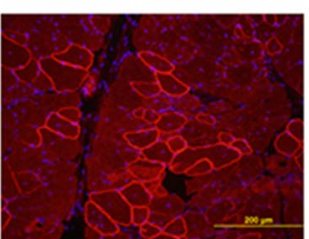

$2 \mathrm{~A}_{2} 1 \mathrm{~B}_{1}+2$ '-OMePS

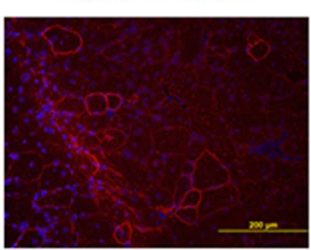

2'-OMePS

b

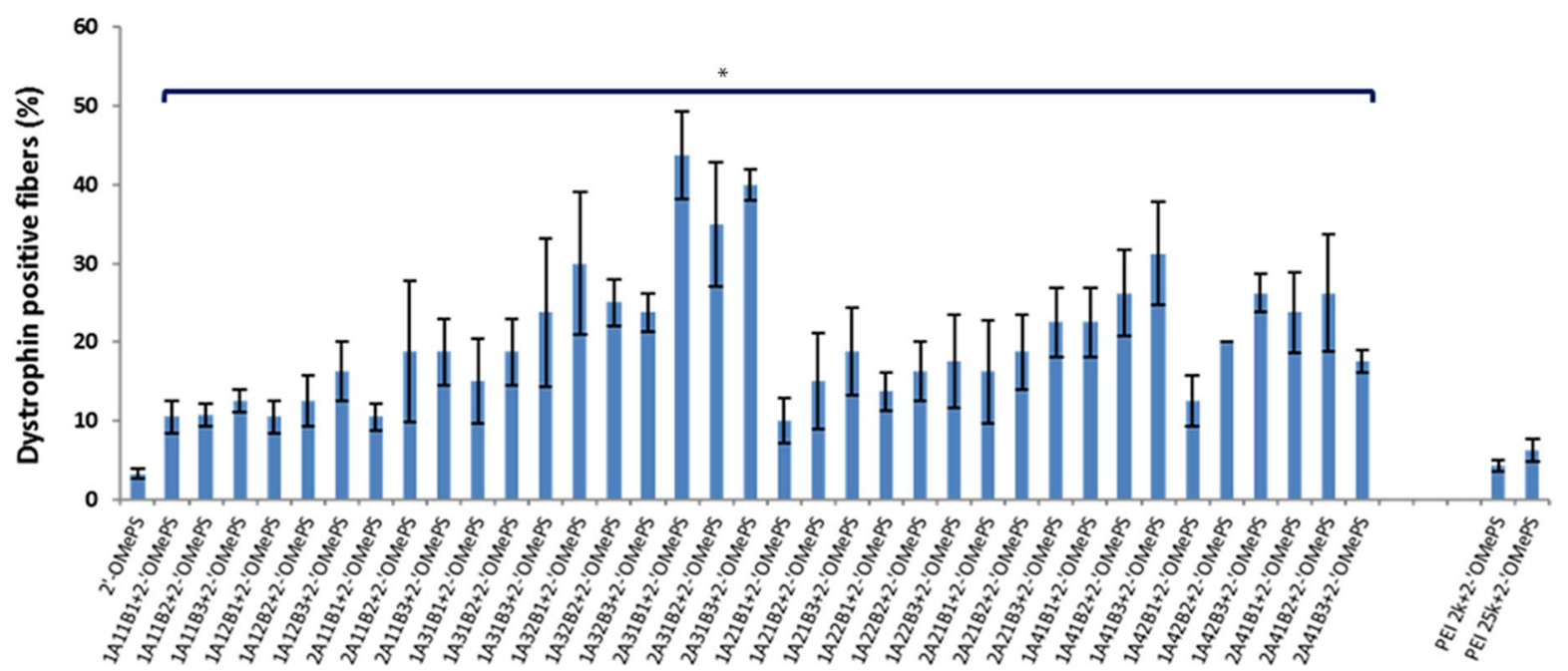

Fig. 7 Restoration of dystrophin in tibialis anterior muscles of $m d x$ mice (aged 4-5 weeks) 2 weeks after intramuscular injection with $20 \mu \mathrm{g}$ polymer formulated 2'-OMePS $(5 \mu \mathrm{g})$ in $40 \mu \mathrm{L}$ saline. Muscles treated with 2'-OMePS only was used as controls. a Dystrophin was detected by immunohistochemistry with rabbit polyclonal antibody P7 against dystrophin. Blue nuclear staining with 4, 6-diamidino-2-phenylindole (original magnification × 200; scale bar $200 \mu \mathrm{m}$ ). $\mathbf{b}$ The percentage of dystrophin-positive fibers (mean $\pm S D, n=5$, Two-tailed t-test, ${ }^{*} p \leq 0.05$ compared with 2'-OMePS) 


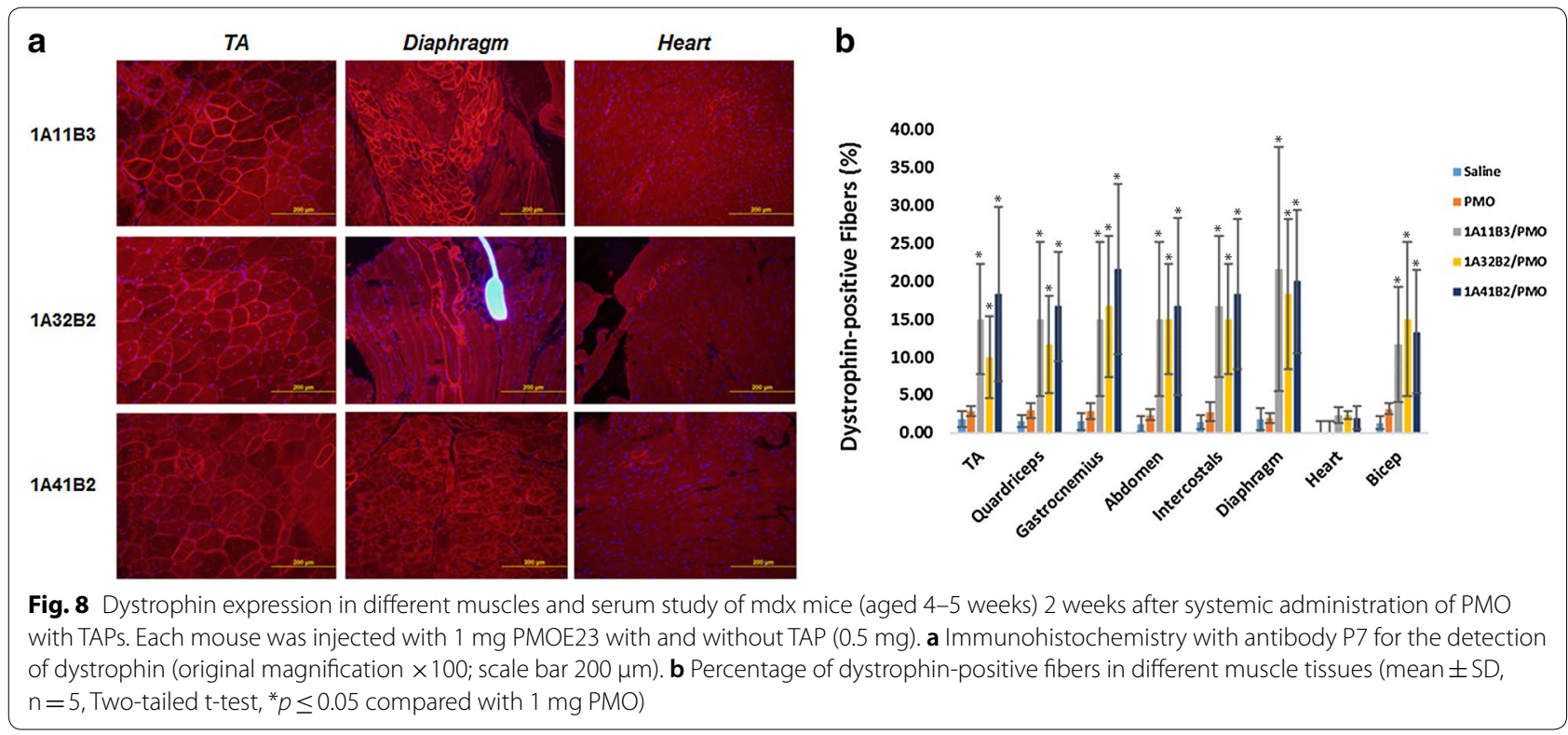

that of PMO, the reason is that the charge-neutral PMO probably has less impediment to cell-surface contact and may thus enter muscle fibers more effectively, particularly those with leaky membrane in the dystrophic muscles $[42,43]$.

\section{Systemic delivery}

DMD-a systemic disease, affects body-wide muscles including cardiac muscle, therefore systemic treatment is indispensable. Based on the results in vivo locally, $1 \mathrm{~A}_{1} 1 \mathrm{~B}_{3}, 1 \mathrm{~A}_{3} 2 \mathrm{~B}_{2}$ and $1 \mathrm{~A}_{4} 1 \mathrm{~B}_{2}$ were further evaluated their effects for PMO systemic delivery by intravenous (i.v.) injection at the dose of $0.5 \mathrm{mg}$ formulated with $1 \mathrm{mg}$ PMOE23 (Fig. 8). The control PMOE23 alone induced dystrophin expression in less than $3 \%$ of muscle fibers in all skeletal muscles and no detectable dystrophin in cardiac muscle 2 weeks after injection. PMOE23 formulated with TAPs produced dystrophin positive fibers $10-22 \%$ in skeletal muscles, with the highest levels around $22 \%$ with $1 \mathrm{~A}_{4} 1 \mathrm{~B}_{2}$ in gastrocnemius muscle and over $20 \%$ with $1 \mathrm{~A}_{1} 1 \mathrm{~B}_{3}$ in diaphragm muscle, respectively. Importantly, immunohistochemistry demonstrated membrane-localized dystrophin in about $1-3 \%$ of cardiac muscle fibers in some areas of the heart treated with the single dose of TAPs. Additionally, the low levels of dystrophin induction in cardiac muscle could be beneficial to the patients, against only occasional one or two positive fibers were observed in cardiac tissue in the mice treated with PMO alone $[7,16]$.

No signs of abnormal behavior or change in body weight and overall condition were observed during treatment with any TAP/AO polyplex in the mice treated both local and systemic delivery. No pathologic changes of the liver, kidney and lung of the treated mice were detected by Hematoxylin and Eosin (H\&E) staining, confirming their low tissue toxicity as demonstrated previously in pDNA delivery [34]. The results suggest that TAPs could be further explored for potential antisense delivery to increase exon-skipping efficiency especially for the treatment of muscular dystrophies.

\section{Conclusions}

The study of triazine-cored amphiphilic polymers for AO delivery in vitro and in $m d x$ mice demonstrated that the carrier's performances are related to the molecular size, compositions and hydrophilic-lipophilic balance (HLB) of the polymers, as well as the AO's chemical structure. In general, the polymers with more lipophilic and higher PEI contents are suitable for negative charged 2'-OMePS delivery; meanwhile, amphiphilic nature is the key as uncharged PMO delivery carrier, though it's hard to conclude the performance correlation between in vitro and in vivo. The variability of individual TAP polymers for delivery of negatively charged pDNA, 2'-OMePS and uncharged PMO highlighted the complexity of the interaction between polymer and the therapeutic agents, the difference in the delivery mechanism. The unique hydrophobic interaction between the TAP polymer and AO creates a more stable complex in primarily hydrophilic environments and further enhances complexplasma membrane interactions both in vitro and in vivo. For the conventional delivery system, all the TAPs have lower toxicity as compared with Endoporter or PEI 25K. Improved exon-skipping efficiency was observed in vitro 
with all TAP polymers and some of them exhibit comparable to or higher than positive control. The in vivo study in $m d x$ mice demonstrated significantly enhanced exonskipping of AO with the TAP polymers compared with AOs alone.

\section{Supplementary information}

Supplementary information accompanies this paper at https://doi. org/10.1186/s12951-020-0586-8.

Additional file 1. 1) Polymer's structure and corresponding code; 2) Comparison of transduction and cytotoxicity between TAP $(10 \mu \mathrm{g})$ and LF-2k (4 $\mu \mathrm{g}$ ) mediated 2'-OMePSE50.

\section{Abbreviations}

TAPs: Triazine-cored amphiphilic polymers; DMD: Duchenne muscular dystrophy; AO: Antisense oligonucleotides; 2'-OMePS: 2'-O-Methyl phosphorothioate RNA; PMO: Phosphorodiamidate morpholino oligomers; HLB: Hydrophilic-lipophilic balance; TEM: Transmission electron microscopy; MTS: 3-(4,5-Dimethylthiazol-2-yl)-5-(3-carboxymethoxyphenyl)-2-(4-sulfophenyl)2H-tetrazolium; LF-2k: Lipofectamine-2000; PEl: Polyethyleneimine; DMEM: Dulbecco's modified Eagle's medium; FBS: Fetal bovine serum; HEPES: 4-(2-Hydroxyethyl)-1-piperazineethanesulfonic acid.

\section{Acknowledgements}

The authors would like to thank Dr. Fei Guo and Dr. David M Foureau for their technical assistance with the flow cytometry and analysis, and Mrs Daisy M Ridings and Ben Wagner from the Electron Microscopy Core Laboratory for the negative staining and transmission electron micrographs.

\section{Authors' contributions}

MW conceived, designed the whole study, and wrote the manuscript. BW supervised and performed the in vivo experiments with SS. JT and PL contributed in cell study. QL, BW and JT reviewed the manuscript. All authors read and approved the final manuscript.

\section{Funding}

Financial support provided by the Carolinas Muscular Dystrophy Research Endowment at the Carolinas HealthCare Foundation and Carolinas Medical Center, Charlotte, NC, USA.

\section{Availability of data and materials}

All data generated or analyzed during this study are included in this article and in Additional file 1

\section{Ethics approval and consent to participate}

All animal studied were performed in accordance with animal protocol procedures approved by the Institutional Animal Care and Use Committee (IACUC), Carolinas Medical Center (Breeding protocol 10-13-07A; Experimental protocol 10-13-08A), which are consistent with the National Institutes of Health Guide for the Care and Use of Laboratory Animals.

\section{Consent for publication}

Not applicable.

\section{Competing interests}

The authors declare that they have no competing interests.

Received: 5 July 2019 Accepted: 29 January 2020

Published online: 18 February 2020

\section{References}

1. Gatheridge MA, Kwon JM, Mendell JM, Scheuerbrandt G, Moat SJ, Eyskens $F$, et al. Identifying non-Duchenne muscular dystrophy-positive and false negative results in prior Duchenne muscular dystrophy newborn screening programs: a review. JAMA Neurol. 2016;73:111-6.

2. Mercuri E, Muntoni F. Muscular dystrophies. Lancet. 2013;381:845-60.

3. Mendell JR, Shilling C, Leslie ND, Flanigan KM, al-Dahhak R, Gastier-Foster J, et al. Evidence-based path to newborn screening for Duchenne muscular dystrophy. Ann Neurol. 2012;71:304-13.

4. Wu B, Moulton HM, Iversen PL, Jiang J, Li J, Spurney CF, et al. Effective rescue of dystrophin improves cardiac function in dystrophin-deficient mice by a modified morpholino oligomer. Proc Natl Acad Sci USA. 2008;105:14814-9.

5. van Deutekom JC, Janson AA, Ginjaar IB, Frankhuizen WS, Aartsma-Rus A, Bremmer-Bout $M$, et al. Local dystrophin restoration with antisense oligonucleotide PRO051. N Engl J Med. 2007;2007(357):2677-86.

6. Kinali M, Arechavala-Gomeza V, Feng L, Cirak S, Hunt D, Adkin C, et al. Local restoration of dystrophin expression with the morpholino oligomer AVI-4658 in duchenne muscular dystrophy: a single-blind, placebo-controlled, dose-escalation, proof-of-concept study. Lancet Neurol. 2009:8:918-28.

7. Goemans NM, Tulinius M, van den Akker JT, Burm BE, Ekhart PF, Heuvelmans N, et al. Systemic administration of PRO051 in Duchenne's muscular dystrophy. N Engl J Med. 2011;364:1513-22.

8. Cirak S, Arechavala-Gomeza V, Guglieri M, Feng L, Torelli S, Anthony $\mathrm{K}$, et al. Exon skipping and dystrophin restoration in patients with Duchenne muscular dystrophy after systemic phosphorodiamidate morpholino oligomer treatment: an open-label, phase 2, dose-escalation study. Lancet. 2011;378:595-605.

9. Yin H, Moulton HM, Seow Y, Boyd C, Boutilier J, Iverson P, et al. Cellpenetrating peptide-conjugated antisense oligonucleotides restore systemic muscle and cardiac dystrophin expression and function. Hum Mol Genet. 2008;17:3909-18.

10. Wu B, Lu P, Benrashid E, Malik S, Ashar J, Doran TJ, et al. Dosedependent restoration of dystrophin expression in cardiac muscle of dystrophic mice by systemically delivered morpholino. Gene Ther. 2009;17:132-40.

11. Wu B, Cloer C, Shaban M, Moulton H, Lu P, Lu Q. Long-term rescue of dystrophin expression and improvement in muscle pathology and function in dystrophic mdx mice by peptide-conjugated morpholino. Am J Pathol. 2012:181:392-400.

12. Sirsi SR, Schray RC, Guan X, Lykens NM, Williams JH, Erney ML, et al. Functionalized PEG-PEI copolymers complexed to exon-skipping oligonucleotides improve dystrophin expression in mdx mice. Hum Gene Ther 2008;19:795-806

13. Lee M, Rentz J, Bikram M, Han S, Bull DA, Kim SW. Hypoxia-inducible VEGF gene delivery to ischemic myocardium using water-soluble lipopolymer. Gene Ther. 2003;10:1535-42.

14. Koo T, Wood MJ. Clinical trials using antisense oligonucleotides in Duchenne muscular dystrophy. Hum Gene Ther. 2013;24:479-88.

15. Eckstein F. Phosphorothioate oligodeoxynucleotides: what is their origin and what is unique about them? Antisense Nucleic Acid Drug Dev. 2000;10:117-21

16. Summerton J, Weller D. Morphoolino antisense oligomers design, preparation, and properties. Antisense Nucleic Acid Drug Dev. 1997:7:187-95.

17. Yano J, Smyth GE. New antisense strategies: chemical synthesis of RNA oligomers. Adv Polym Sci. 2012;249:1-48.

18. 't Hoen PA, van der Wees CG, Aartsma-Rus A, Turk R, Goyenvalle A, Danos $\mathrm{O}$, et al. Gene expression profiling to monitor therapeutic and adverse effects of antisense therapies for duchenne muscular dystrophy. Pharmacogenomics. 2006;7:281-97.

19. Hoffman EP. Skipping toward personalized molecular medicine. N Engl J Med. 2007;357:2719-22

20. Jirka SM, Heemskerk H, Tanganyika-de Winter CL, Muilwijk D, Pang KH, de Visser PC, et al. Peptide conjugation of phosphorothioate antisense oligonucleotides enhances cardiac uptake and exon skipping in $\mathrm{mdx}$ mice. Nucleic Acid Ther. 2014;24(1):25-36.

21. Hunt KK, Vorburger SA. Hurdles and hopes for cancer treatment. Science. 2002;297:415-6.

22. Pack DW, Hoffman AS, Pun S, Stayton PS. Design and development of polymers for gene delivery. Nat Rev Drug Discov. 2005;4:581-93.

23. Kwok A, Eggimann GA, Reymond JL, Darbre T, Hollfelder F. Peptide dendrimer/lipid hybrid systems are efficient dna transfection reagents: 
structure-activity relationships highlight the role of charge distribution across dendrimer generations. ACS Nano. 2013;7:4668-82.

24. Davis ME, Zuckerman JE, Choi CHJ, Seligson D, Tolcher A, Alabi CA, et al. Evidence of RNAi in humans from systemically administered siRNA via targeted nanoparticles. Nature. 2010;464:1067-70.

25. Lu Q, Bou-Gharios G, Partridge TA. Non-viral gene delivery in skeletal muscle: a protein factory. Gene Ther. 2003;10:131-42.

26. Lemieux P, Guerin N, Paradis G, Proulx R, Chistyakova L, Kabanov A, et al. A combination of poloxamers increases gene expression of plasmid DNA in skeletal muscle. Gene Ther. 2000;7:986-91.

27. Pitard B, Pollard H, Agbulut O, Lambert O, Vilquin JT, Cherel Y, et al. A nonionic amphiphile agent promotes gene delivery in vivo to skeletal and cardiac muscles. Hum Gene Ther. 2002;13:1767-75.

28. Cho KC, Choi SH, Park TG. Low molecular weight PEl conjugated pluronic copolymer: useful additive for enhancing gene transfection efficiency. Macromol Res. 2006;14:348-53.

29. Nguyen HK, Lemieux P, Vinogradov SV, Gebhart CL, Guerin N, Paradis G, et al. Evaluation of polyether-polyethyleneimine graft copolymers as gene transfer agents. Gene Ther. 2000;7:126-38.

30. Wang M, Wu B, Lu P, Tucker JD, Cloer C, Lu Q. Polyethylenimine-modified pluronics (PCMs) improve morpholino oligomer delivery in cell culture and dystrophic mdx mice. Mol Ther. 2013;21:210-6.

31. Wang M, Wu B, Tucker JD, Lu P, Cloer C, Lu Q. Evaluation of tris[2(acryloyloxy)ethyl]isocyanurate cross-linked polyethylenimine as antisense morpholino oligomer delivery vehicle in cell culture and dystrophic mdx mice. Hum Gene Ther. 2014;25(5):419-27.

32. Wang $M, W u B$, Tucker JD, Lu P, Bollinger LE, Lu Q. Tween 85 grafted PEls enhanced delivery of antisense $2^{\prime}-O$-methyl phosphorothioate oligonucleotides in vitro and in dystrophic mdx mice. J Mater Chem B. 2015;3:5330-40.

33. Wang M, Wu B, Tucker JD, Lu P, Lu Q. Cationic polyelectrolyte-mediated delivery of antisense morpholino oligonucleotides for exon-skipping in vitro and in mdx mice. Inter J Nanomed. 2015;10:5635-46.

34. Wang M, Bo W, Tucker JD, Lu P, Lu Q. A combinatorial library of triazinecored polymeric vectors for pDNA delivery in vitro and in vivo. J Mater Chem B. 2017;5:3907-18.
35. Wang M, Wu B, Tucker JD, Bollinger LE, Lu P, Lu Q. Poly (ester amine) composed of polyethylenimine and pluronic enhance delivery of antisense oligonucleotides in vitro and in dystrophic mdx mice. Mol Ther Nucleic Acids. 2016;5:e341.

36. Akhtar S, Benter IF. Nonviral delivery of synthetic siRNAs in vivo. J Clin Invest. 2007;117:3623-32.

37. Juliano RL, Bauman J, Kang H, Ming X. Biological barriers to therapy with antisense and siRNA oligonucleotides. Mol Pharm. 2009;6:686-95.

38. Juliano RL, Ming X, Nakagawa O. Cellular uptake and intracellular trafficking of antisense and siRNA oligonucleotides. Bioconjug Chem. 2012:23:147-57.

39. Forrest ML, Meister GE, Koerber JT, Pack DW. Partial acetylation of polyethylenimine enhances in vitro gene delivery. Pharm Res. 2004;21:365-71.

40. Sazani P, Kang SH, Maier MA, Wei C, Dillman J, Summerton J, Manoharan $\mathrm{M}$, Kole R. Nuclear antisense effects of neutral, anionic and cationic oligonucleotide analogs. Nucleic Acids Res. 2001;29:3965-74.

41. Hu Y, Wu B, Zillmer A, Lu P, Benrashid E, Wang M, Doran T, Shaban M, Wu X, Lu Q. Guanine analogues enhance antisense oligonucleotideinduced exon skipping in dystrophin gene in vitro and in vivo. Mol Ther. 2010;18(4):812-8.

42. Lu Q, Rabinowitz A, Chen YC, Yokota T, Yin H, Alter J, et al. Systemic delivery of antisense oligoribonucleotide restores dystrophin expression in body-wide skeletal muscles. Proc Natl Acad Sci USA. 2005;102:198-203.

43. Alter J, Lou F, Rabinowitz A, Yin H, Rosenfeld J, Wilton SD, et al. Systemic delivery of morpholino oligonucleotide restores dystrophin expression bodywide and improves dystrophic pathology. Nat Med. 2006;12:175-7.

\section{Publisher's Note}

Springer Nature remains neutral with regard to jurisdictional claims in published maps and institutional affiliations.
Ready to submit your research? Choose BMC and benefit from:

- fast, convenient online submission

- thorough peer review by experienced researchers in your field

- rapid publication on acceptance

- support for research data, including large and complex data types

- gold Open Access which fosters wider collaboration and increased citations

- maximum visibility for your research: over 100M website views per year

At BMC, research is always in progress.

Learn more biomedcentral.com/submissions 